\title{
AS REPRESENTACÕES SOCIAIS DOS LICENCIANDOS DE FÍSICA REFERENTES À INCLUSÃO DE DEFICIENTES VISUAIS
}

\author{
Maria da Conceição de Almeida Barbosa Lima* \\ Maria Auxiliadora Delgado Machado**
}

RESUMO: Este trabalho estuda a disciplina Ensino de Física e Inclusão Social criada há três anos como eletiva no curso de Licenciatura em Física. Pretendemos conhecer o que os licenciandos pensam de um ensino de Física inclusivo enquanto estão na Universidade, para eventuais mudanças no curso. Utilizamos Grupo Focal articulado ao Discurso do Sujeito Coletivo para identificar as representações sociais. O resultado mostrou que o tema inclusão não mobiliza os licenciandos, não constituindo uma representação social. Por outro lado, a ideia de o ensino de Física estar associado com dificuldade que só pode ser enfrentada por estudantes segundo um padrão de normalidade é um objeto de representação social, uma vez que se apresentou como um fenômeno capaz de gerar concepções, opiniões e atitudes ora contraditórias ora convergentes. Esse resultado é um indicador de que nossos estudantes ainda não aceitam que deficientes visuais possam aprender Física.

Palavras-chave: Representação social, ensino de Física, inclusão social.

\section{SOCIAL REPRESENTATIONS OF UNDERGRADUATE PHYSICS STUDENTS REGARDING SOCIAL INCLUSION OF VISUALLY IMPAIRED PERSONS}

ABSTRACT: This work investigated the discipline Physics Teaching and Social Inclusion, created three years ago as an elective in the Bachelor's Degree in Physics. Our objective was to determine the opinion of students about inclusive education in Physics at the university, for possible changes in the course. We used Focus Group and Discourse of the Collective Subject to identify social representations. The results showed that inclusion is not a topic that mobilizes undergraduate students, and does not constitute a social representation. On the other hand, the notion that Physics teaching is associated with difficulties that can only be confronted by students who conform to a normal pattern represents an object of social representation, because it generated both contradictory and convergent concepts, views and behaviors. This result indicates that our students still do not accept that visually impaired persons can learn Physics.

Keywords: Social Representation, Physics Teaching, Social Inclusion.

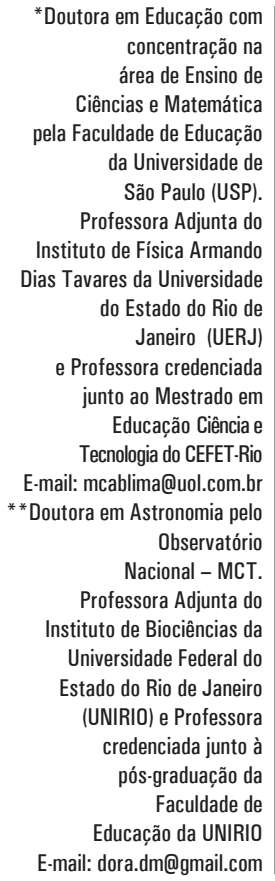




\section{INTRODUÇÃO}

A assembléia da UNESCO ocorrida na Espanha em 1994 produziu um documento, a Declaração de Salamanca (UNESCO, 1994), que formaliza a proposta, oriunda de movimentos sociais emergentes em todo o mundo que se norteavam pela ideia de uma sociedade inclusiva. Partiram do pressuposto de que diferenças de qualquer natureza têm uma implicação direta para a estrutura das sociedades, inclusive a escola, sendo então estendido a todas as minorias (Claser, 2001).

No Brasil, a questão da inclusão de pessoas com deficiência em salas de aula, conforme previsto pela LDB, Lei de Diretrizes e Bases da Educação Nacional, que nos fornece os deveres e direitos dos cidadãos brasileiros quanto à escolarização (BRASIL, 1996), é um assunto que tem despertado um interesse crescente e já conta com uma base teórica significativa, que abrange as diversas deficiências, discutidas em trabalhos como os de Sassaki (1997), Stainback e Stainback (2000), Freitas e Soares (2002), entre outros. No que se refere especificamente à inclusão de deficientes visuais, observamos que a maioria dos artigos aborda diversos aspectos do cotidiano da sala de aula, como as relações de professores e alunos com os alunos com deficiência visual, ou seja, as estratégias relacionadas ao ensino-aprendizagem (CAMARGO 2008). Por outro lado, existe uma forte lacuna de discussões sobre a formação do professor responsável pelo processo de inclusão no ensino médio. Artigos, como o de Camargo (2008), que retratam o processo formativo dos licenciandos de Física em relação aos deficientes visuais, ainda são exceções.

De certa forma, esse cenário reflete que, a despeito de o ingresso de alunos com deficiências visuais ser garantida por lei, não há nenhuma previsão nos textos normativos sobre a formação continuada dos professores para lidar com essa nova realidade na sala de aula. O ensino para um deficiente visual ainda está fortemente relacionado à idéia de "enfrentar as diferenças", entendendo-se por "diferença" qualquer situação que se distancie do senso de "normalidade", e como consequência às dificuldades em se trabalhar, em qualquer âmbito, com essas diferenças.

A questão da formação, necessária a um professor pela perspectiva de receber um deficiente em sua sala de aula, pode se tornar mais complexa quando se trata de um professor de Física, uma vez que as dificuldades são consideradas por alguns como intransponíveis, produzindo questionamentos sobre a necessidade de um aluno com deficiência visual estudar Física. Outro ponto importante nessa reflexão é que, no curso de licenciatura em Física, os estágios ocorrem no último ano do curso em completa defasagem com o que foi ensinado nos anos anteriores, dentro do cenário da racionalidade técnica. Nesse tipo de licenciatura, os estudantes passam por duas situações díspares e estanques: a primeira na qual geralmente dividem espaço físico, grade curricular e professores com cursos de bacharelado, assistindo a disciplinas de conteúdo específico de sua área de conteúdo; e a segunda por meio da qual, quase ao fim de sua jornada, entram em contato com disciplinas pedagógicas e com estágios. Diante desse cenário marcado por tantas dicotomias, surge a seguinte pergunta: como discutir inclusão social nos cursos de licenciatura em Física? 
A tentativa de responder a essa pergunta cria uma oportunidade inicial de argumentação para se tecerem as bases teóricas relativas à formação de um professor inclusivo, e cuja resposta passa pelas seguintes ações: a) Incentivar a participação dos licenciandos nos estágios do cotidiano escolar a partir de parcerias universidade-escola, onde os problemas sejam discutidos de forma circular, ou seja, onde os saberes dos professores da universidade e da escola sejam norteadores do processo reflexivo do aluno que passa a assumir uma postura crítica e transformadora diante das situações vivenciadas (CACHAPUZ, 2008), b) Oferecer essas oportunidades na forma de estágios ou de outra participação, cada vez mais cedo, ao longo do processo formativo do licenciando, a fim de se criar uma cultura crítica-reflexiva já na formação inicial.

Foi com esse espírito que uma das autoras criou em 2007 a disciplina eletiva Ensino de Física e Inclusão Social, no Instituto de Física na Universidade com objetivo de: i) promover a discussão e a informação sobre as distintas "diferenças" presentes na sociedade e projetadas na escola; ii) a partir da familiarização dos alunos com os novos aspectos trazidos pela disciplina, incentivar a reflexão sobre como algumas questões devem ser tratadas na prática.

Desde sua criação, a disciplina vem permitindo a construção sistemática de um novo saber que incorpora elementos do conteúdo de Física, de pedagogia e elementos trazidos pelo contato direto com deficientes visuais e/ou professores que trabalhem com esses alunos, convidados a participar de alguma aula do curso. Dos alunos que passaram pelo curso, alguns se interessaram em aprofundar seus estudos em torno da inclusão de deficientes visuais em aulas de Física e desenvolveram e/ou estão desenvolvendo trabalho de monografias de graduação e dissertações de mestrado. Esse número já é bastante representativo e mostra a força do tema e suas diferentes possibilidades de abordagem no campo da pesquisa.

Depois de oferecer o curso por sete semestres consecutivos, com resultados já promissores na área de pesquisa, nos pareceu pertinente fazer uma metareflexão para verificar como a disciplina está contribuindo para a formação docente do licenciando de Física no sentido de sinalizar os caminhos de uma prática docente transformadora.

Não queremos conhecer as idéias dos professores, mas dos licenciandos. $\mathrm{O}$ que eles pensam acerca de um ensino de Física inclusivo enquanto convivem no ambiente universitário no qual se dá seu processo de formação, contexto fundamental para nossa reflexão, e eventuais inferências na estrutura do curso.

A questão imediata que surgiu foi qual seria a metodologia adequada para produzir um conjunto de informações objetivas e organizadas, passíveis de serem analisadas no contexto desejado e eventualmente que pudessem ser consideradas para a reestruturação do curso, caso concluíssemos por essa necessidade. A resposta a essa questão está diretamente relacionada a dois pressupostos básicos em nossa pesquisa: i) os licenciandos possuem idéias próprias sobre ensino inclusivo, construídas a partir de suas realidades de vida e ii) tais idéias, como é próprio do que chamamos de senso comum, não são facilmente identificadas em informa- 
ções isoladas e estanques obtidas através de questionários ou entrevistas onde as questões abertas ou não refletem de alguma forma as ideias dos pesquisadores.

Para estabelecer este cenário optamos pela técnica do Grupo Focal que consiste em uma técnica de coleta de dados diretamente das falas dos participantes do grupo, associando o uso dessa técnica ao aporte metodológico da análise do Discurso do Sujeito Coletivo com objetivo de identificar as Representações Sociais.

O objetivo desse trabalho é identificar as representações dos licenciandos que são mobilizadas pela idéia de inclusão dos deficientes e sua importância para a tessitura de um referencial teórico referente ao ensino de Física para deficientes visuais.

\section{CAMINHOS TEÓRICO-METODOLÓGICOS}

Este trabalho resulta de uma pesquisa qualitativa, que deve ser entendida como aquela capaz de incorporar a questão do significado e da intencionalidade como inerentes aos atos, às relações e às estruturas sociais, sendo as últimas consideradas, tanto no seu advento quanto na sua transformação, como construções humanas significativas (MINAYO, 1992). Nesse tipo de pesquisa a busca de respostas para os problemas que inquietam os pesquisadores não podem se apoiar em receitas definidas previamente ou instrumentos utilizados por outros investigadores em outros contextos. Ao contrário, os caminhos a serem seguidos durante o processo investigativo devem ser definidos, considerando as especificidades da realidade abordada. A metodologia proporciona o caminho e o instrumental próprios de abordagem dessa realidade e segundo Minayo (1992, p.22) “ocupa o lugar central no interior das teorias sociais, pois ela faz parte intrínseca da visão social do mundo veiculada na teoria".

Conforme os objetivos de nossa pesquisa, a reflexão e mesmo o embate de opiniões divergentes de um grupo de licenciandos sobre ensino de Física inclusivo, necessários à execução do trabalho, implicavam em coleta de dados diretamente das falas dos participantes do grupo que, no contexto da interação grupal, ao contrário de entrevistas individuais, permitem a compreensão do processo de construção das percepções, atitudes e representações do grupo acerca de um tema e que os depoimentos individuais não fossem anulados ou reduzidos a uma categoria comum unificadora, garantindo a construção de um discurso representativo desse grupo.

A teoria das Representações Sociais (RS) criada por Moscovici se constitui em uma modalidade de conhecimento particular que circula no dia-a-dia e que tem como função a elaboração de comportamentos e a comunicação entre indivíduos (MOSCOVICI, 1978). As RS articulam elementos mentais, sociais e afetivos, vinculando a cognição, a comunicação e a linguagem com as relações sociais que intervêm nestas representações em diversas áreas do conhecimento humano (JODELET, 1989).

O conceito de RS é polissêmico (MOSCOVICI, 1978) e essa característica é continuamente reafirmada nos processos de revisão do tema, disponíveis na 
literatura (WACHELKE; CAMARGO, 2007). Mesmo sem uma plena concordância sobre sua definição, as RS estão fortemente relacionadas às teorias do senso comum que são construídas e compartilhadas coletivamente e "... cujas funções são tanto de enquadramento dos objetos sociais em sistemas hierárquicos estruturados de relativa estabilidade, quanto de prescrição para guiar ações e interações sociais (GONDIM, 2009)".

Segundo Gondim (2009), as RS se constituem na base teórica da estratégia metodológica do Discurso do Sujeito Coletivo (DSC) (LEFÈVRE e LEFÈVRE 2000) para quem o imaginário social compartilhado pelo coletivo em um determinado momento se reflete nos pensamentos, opiniões e respostas emitidos pelos componentes desse coletivo diante de certas questões. Nesse sentido, as expressões individuais não representam somente o pensamento de um indivíduo, mas são reveladoras dos elementos que compõe o imaginário coletivo de um grupo. E é a partir dessas expressões individuais que a análise do discurso do sujeito coletivo busca identificar as representações de um grupo social num dado momento.

A técnica consiste na organização de dados discursivos a partir de figuras metodológicas nomeadas como ancoragem, expressões-chave e ideia central. A ancoragem deve ser entendida como a característica mais geral de um dado discurso, na qual se identifica a sua ideia central pela presença de expressõeschave. As expressões-chave são segmentos contínuos ou descontínuos de discurso que revelam o principal conteúdo discursivo e a idéia central é a síntese do conteúdo dessas expressões.

As pesquisas em RS têm se caracterizado por uma busca diversificada de estratégias no que se refere à forma mais adequada de coleta de dados em função do tema que se deseja investigar, o que fundamenta o emprego das técnicas do GF para a coleta dos dados utilizados nesse trabalho.

\section{ORGANIZANDO 0 GRUPO FOCAL}

A organização do grupo focal foi feita a partir do artigo de Gondim (2003). Nessa perspectiva, concluímos que o grupo focal mais adequado ao nosso trabalho era o de tipo exploratório, centrado na produção de conteúdos e cuja orientação teórica está voltada para a geração de hipóteses, enquanto a prática tem como alvo a produção de novas ideias. Optamos por uma abordagem hermenêutica que, segundo a autora, "se apóia na interpretação, na linguagem e no discurso, gerando um tipo de conhecimento válido a partir da compreensão do significado do contexto particular" (Gondim 2003, p.150).

O grupo focal foi constituído por seis licenciandos de Física entre os quais três cursaram a disciplina, dois não cursaram e um ainda estava cursando, além de dois professores recém formados e que também a tinham cursado. Dessa forma temos um grupo focal heterogêneo, o que facilita a emergência de informações on crenças não compartilhadas e, devido à importância pessoal do tema, os participantes tendem a 
adotar posições menos flexiveis do que nos grupos mais homogêneos (Gondim 2003, p.156). No sentido de uma melhor compreensão desse texto, os participantes do grupo focal serão tratados por licenciandos, apesar da presença de dois ex-alunos do curso de licenciatura, que na época da coleta de dados já eram professores.

Os contatos com os licenciandos foram feitos através de convites eletrônicos nos quais constavam, além do dia, local e hora da reunião. No dia da realização do Grupo Focal, os licenciandos assinaram um termo de consentimento.

A dinâmica do Grupo Focal foi dirigida por uma moderadora (uma das autoras) e consistiu basicamente de quatro momentos. Primeiro momento: no qual a moderadora apresentou os objetivos do trabalho, pediu aos participantes que se apresentassem; segundo momento: a moderadora iniciou a discussão provocando um embate através da colocação para o grupo de duas frases, aparentemente ambíguas, que foram retiradas das falas de dois professores da escola básica, sem nenhuma relação com a disciplina e que consistiram do seguinte: "A inclusão é exclusiva" x "todo mundo ganha quando tem um cego em sala de aula". Essa técnica, também conhecida como Indução por Cenário Ambíguo (MOLINER, 1992), objetiva identificar a hierarquia entre os elementos de uma representação social, que pode eventualmente se constituir de elementos considerados como o núcleo central da representação e de outros assumidos como periféricos. Apesar desse tipo de detalhamento não se constituir no objetivo deste trabalho, o fato de essa técnica contrapor idéias antagônicas é muito eficiente como uma estratégia provocadora inicial de discussão.Terceiro momento: a moderadora norteia a discussão a partir de quatro questões, propostas no decorrer do grupo focal que foram as seguintes: i) recursos em sala para ensinar Física a uma deficiente visual, ii) qual conteúdo de Física que você considera mais difícil de ensinar a um deficiente visual? iii) em que você pensa ao considerar a presença de um deficiente visual em sala, iv) fale sobre a disciplina.

\section{CONSTRUINDO E ANALISANDO OS DISCURSOS DO SUJEITO COLETIVO}

A intensa discussão gerada pelo cenário ambíguo foi mais polêmica do que imaginávamos, resultando na recorrência de alguns elementos dessa discussão nas falas dos licenciandos ao longo do grupo focal. Devido a essa reação do grupo, não foi possível construir DSCs específicos para cada momento relativo a cada uma das outras questões colocadas, que a princípio poderiam ter funcionado como ancoragens dos DSCs. Esse fato dificultou um pouco a construção dos DSCs, mas, por outro lado, nos mostrou a riqueza de significados presentes nos discursos.

Nos quadros abaixo, apresentamos os DSCs construídos com as expressões-chave obtidas nos discursos para cada uma das idéias centrais das ancoragens identificadas e a seguir comentamos sobre cada um deles. 
Quadro 1: DSC construído a partir da ancoragem RESPONSABILIDADE DO PROFESSOR

IDEIA CENTRAL N. 1

ESFORC̣O

0 professor tem que vencer uma guerra sozinho..., a escola pode até se propor a fazer alguma coisa, mas tem mesmo a ver com a dedicação do professor, pois se ele não tiver consciência da situação que ele está vivendo, ele não vai fazer nada. Além disso o professor tem que ter conhecimento do assunto. ...ele se formou e não aprendeu nada sobre 0 assunto, não está preparado, mas tem que se preparar para não ser pego de surpresa,a iniciativa é do professor, ele deve correr atrás e não ficar esperando acontecer, independente de tempo, buscar cursos de extensão, para ter uma outra postura, uma iniciativa diferente, não pode esperar vir tudo na mão.

IDEIA CENTRAL N. 2

NATURALIDADE

0 aluno cego é só mais um aluno na minha realidade, é só mais um deficiente, tem aluna que foi estuprada, aluno que o pai é traficante passa fome, tem várias deficiências. Só que sobre o cego, esse eu tenho certeza sobre a limitação dele, ele é cego! Precisamos preparar alguma coisa. Terá momentos que não vai dar pra dar aula. Tem que bolar. Dá trabalho. Trabalho igual para os alunos videntes.

Nos relatos produzidos em resposta ao cenário ambíguo, identificamos claramente uma ancoragem que designamos como responsabilidade do professor, na qual é explicitada que o êxito da tarefa de ensinar a um aluno com deficiência visual é de responsabilidade do professor, sem fazer menção a escola, família, ou poder público. Nessa ancoragem se formam duas ideias centrais. O DSC construído a partir da ideia central esforço do professor é claramente uma resposta à primeira frase do cenário ambíguo "A inclusão é exclusiva", expressa na forma de uma crítica contundente aos professores que venham a ter reações semelhantes. Fica claro pelos termos grifados no DSC relativo a essa ideia central uma cobrança de iniciativa do professor como se a situação dissesse respeito exclusivamente ao professor.

O segundo DSC produzido nessa ancoragem tem como ideia central uma postura de naturalidade. O tom do discurso produzido nessa ideia central é mais brando e se constrói a partir do fato que a deficiência visual deva ser encarada naturalmente como outras deficiências presentes no cotidiano. Apesar do tom menos crítico desse segundo DSC, o foco da responsabilidade pela inclusão do aluno com deficiência visual ainda está sobre o professor.

Vale ressaltar que as falas dos licenciandos durante a discussão do cenário ambíguo, foram as únicas, durante todo o grupo focal, proferidas na terceira pessoa, evidenciando uma crítica a um professor com o qual eles não se identificam e a quem eles associam uma idéia de fracasso em relação ao ensino de alunos com deficiência visual. O DSC é uma construção na primeira pessoa, porém nós decidimos não alterar a pessoa do discurso produzido a fim de ressaltar o tom crítico desse discurso. 
Quadro 2: DSC construído a partir da ancoragem PADRÃO DAS AULAS

IDEIA CENTRAL N. 1

RECURSOS PEDAGÓgICOS

0 nosso trabalho é apegado a recursos visuais. É quadro negro. É vetor. É desenho. Toda a Física é construída com desenhos e gráficos. Eu não abriria mão do quadro negro porque o quadro já é um recurso áudio visual. Porque quando a gente pensa em uma turma inclusiva a gente não pode esquecer que tem outros alunos nessa turma e a aula tradicional pode ser muito criticada por muitos, mas ela tem seu valor. Tem que se reconstruir todo o seu planejamento do ano se você não pode contar com os seus recursos visuais. É um baque. Temos que buscar experimentos táteis Mas mesmo que a Física fique comprometida vale a pena.

IDEIA CENTRAL N. 2

CONTEÚDO

Não mudar a aula tradicional, acrescentar alguma coisa, mas não mudar, pois a aula tradicional tem seu valor. Não abro mão de conteúdos em função da qualidade. Reduzir muito o programa, porque os caras vão ter que sair de lá e vão ter que encarar uma faculdade como todos os outros, fazer a prova do vestibular que infelizmente nossa realidade é essa. A parte mais difícil é Ótica, é bem abstrato, até para os videntes com uma base pobre de geometria. Para que eles (os alunos com deficiência visuais) precisam aprender cor? Campo elétrico também tem conceitos muito difíceis, até para os professores. Você tem que saber adaptar o conteúdo não só para os alunos com deficiência visual, mas para todos. Não pode tirar nada, fala superficialmente, mas fala.

IDEIA CENTRAL N. 3

CURRíCULO

Tem que adaptar 0 currículo para todos os alunos, com deficiência visual ou não. Atualmente se fala de incluir Física Moderna e Contemporânea no currículo que já está inchado. Tem que pensar em coisas que não são usadas. Para que aprendemos números complexos, quando vamos usá-los? Mas Ótica é importante, tem elementos do dia a dia, ele (o aluno com deficiência visual) ouve falar de espelho e tem que pensar nos que não nasceram cegos ou têm baixa visão, o conceito de cor, fotografia, espelho, faz parte do dia a dia.

A segunda ancoragem evidencia questões que, segundo os licenciandos, estão relacionadas a uma boa aula, e na qual eles consideram, pela primeira vez no grupo focal, as especificidades de uma aula de Física, possivelmente em resposta à primeira questão proposta pela mediadora. O DSC produzido na primeira idéia central mostra a força do quadro de giz como um elemento representativo dos recursos visuais em uma aula de Física, no qual está centrado todo o planejamento. A busca por recursos pedagógicos táteis parece a única saída para se tratar o aluno com deficiência visual, e sua utilização certamente comprometerá o conteúdo de Física a ser ensinado.

A preocupação com o conteúdo consiste na segunda idéia central e é bastante recorrente. Fica evidente a preocupação dos licenciandos com o fato de algumas partes do conteúdo de Física serem inadequadas aos alunos com deficiência visual, como ótica e magnetismo. Porém o desenrolar do discurso aponta que essas inadequações refletem o próprio despreparo de cada um dos licenciandos, ou seja, os conteúdos considerados difíceis de serem ensinado aos alunos com deficiência visual são os conteúdos que eles, os licenciandos, não dominam e que também não seriam bem ensinados àqueles alunos.

Essa autocrítica não é feita e o conteúdo da disciplina é fortemente relacionado a um rigor, segundo os licenciandos, característico do ensino de Física, justifi- 
cando a defesa de um ensino nos moldes tradicionais, com vistas ao vestibular.

Um discurso contrário a essa visão tradicionalista só aparece na terceira idéia central que é o currículo. Nesse momento são explicitadas preocupações com a realidade do aluno, seja ele um aluno com deficiência visual ou não, e a possibilidade de repensar esse currículo em função dos fatos que permeiam o cotidiano, expressando aí uma visão bastante pragmática da ciência, muito comum à ciência da sala aula.

Quadro3: DSC construído a partir da ancoragem CONTATO COM ALUNOS COM DEFICIÊNCIA VISUAL

IDEIA CENTRAL N. 1

\section{TRABALHAR COM UM ALUNO COM DEFICIÊNCIA VISUAL EM SALA}

Não ter medo de errar. A ansiedade do primeiro contato é inevitável. Lembrar que na universidade tem bons referenciais para nos ajudar. É questão de bom senso do professor para lidar com as diferenças entre todos os alunos da turma. E pensar que é sempre assim, uma aula que foi boa para um não foi boa pra outro. Prestar atenção na reação do aluno. No começo eu vou dar uma atenção especial e depois vou achar natural. Mesmo porque ele não precisa aprender tudo, é muito mais importante ele estar ali do que aprender tudo. Eu não aprendi tudo.

IDEIA CENTRAL N. 2

IMPACTO DO CURSO

As disciplinas que a gente tem (na licenciatura) deveriam chamar a atenção para a possibilidade da presença de portadores de diferenças em sala. Mas isso não ocorre. 0 professor da universidade não conhece a LDB, ninguém fala disso. 0 professor da universidade que não tem licenciatura deveria se informar mais. A gente faz a licenciatura e chega lá na hora tem um aluno cego, e aí? 0 que a gente faz? Por isso a disciplina

"inclusão" é importante, pois ela mostra que essa realidade existe e que é possível enfrentar a situação com um aluno com deficiência visual presente, mas o curso deveria ter mais prática, e os trabalhos deviam ser avaliados por alunos com deficiência visual.

A terceira ancoragem surge da percepção de uma mudança no tom discursivo dos licenciandos em relação àquele da primeira ancoragem, quando a discussão gira em torno da possibilidade real de receber uma pessoa com deficiência visual como aluno. Nessa ancoragem foram identificadas duas idéias centrais, a ação docente e o impacto do curso. O discurso produzido na primeira idéia central novamente remete à sala de aula e às relações aluno-professor que ocorrem em sala. Um fator que chama a atenção no DSC relativo a essa idéia central é que os licenciandos abandonam a postura crítica que eles assumiram ao falar "do professor", se expressando inclusive na primeira pessoa e não mais na terceira, como na IC1 da primeira ancoragem. Além disso, nesse momento da discussão, eles se mostram mais condescendentes com o contato com o diferente, mesmo assumindo um estado de grande ansiedade em relação a essa possibilidade. Apesar desse tom mais aberto, externando disposição em trabalhar com os alunos com deficiência visual, o trecho "Mesmo porque ele não precisa aprender tudo, é muito mais importante ele estar ali do que aprender tudo. Eu não aprendi tudo" é revelador de um tipo de exclusão, rodeada por um sentimento de cumprimento de uma obrigação. A visão a que essa fala remete é que passa a ser natural que alguns alunos fiquem em sala sem aprender e que a educação plena seja possível somente para uns poucos, nos remetendo ao 
conceito de educação bancária de Paulo Freire (1987)

A segunda ideia central dessa ancoragem, o impacto do curso, foi provocada com uma pergunta de encerramento para nos fornecer um retorno em relação a eventuais modificações no curso. $\mathrm{O}$ discurso produzido nos proporciona a possibilidade de observar a crítica do licenciando ao sistema universitário que o está formando. É como se revelasse sua indignação de passar tanto tempo na universidade desconhecendo a LDB e sem, em momento nenhum de sua formação, durante as disciplinas de conteúdos específicos da área de Física, ter sido sequer alertado sobre essa possibilidade. Chamamos a atenção que a referência à LDB nesse discurso foi a única referência feita às políticas públicas durante todo o grupo focal, deixando claro que o licenciando não tem intimidade com essa questão, e consequentemente esse assunto não fez parte de sua formação.

Esse discurso também revela que a interface dos licenciandos de Física com os cursos da área pedagógica não aborda essa questão, fato preocupante, pois a formação nesta área forma o professor em conjunto com a área de conteúdo. Se esse profissional também não discute a inclusão, é fácil imaginar que o ambiente escolar será marcado pela falta de preparo e às vezes até disposição, justificando, de certa forma, a frase "a inclusão é exclusiva", usada no cenário ambíguo.

A demanda por mais práticas e por um contato direto com os alunos com deficiência visual será considerada para os próximos cursos e sinaliza como esses alunos com deficiência visual ainda estão ausentes do cotidiano de boa parte da sociedade.

\section{REFLETINDO SOBRE OS DISCURSOS PRODUZIDOS}

A partir das ações desenvolvidas neste trabalho, desde a realização do grupo focal, passando pela transcrição das falas, até a análise para construção do DSC, concluímos que o tema "Ensino Inclusivo de Física para alunos com deficiência visual" não é colocado diretamente no foco da discussão dos licenciandos, que abordam muito mais a questão das diferenças que esses alunos representam em comparação aos alunos sem deficiência visual, ou seja, a turma.

As idéias manifestadas pelo grupo remetem a um padrão de ensino fortemente alicerçado em um êxito baseado em um ensino onde o conteúdo é elemento principal e o quadro de giz aparece como centralizador da ação docente. A consideração da presença dos alunos com deficiência visual em sala é discutida do ponto de vista, não das características específicas do aluno, mas da revolução que eles podem causar ao planejamento das aulas. Além disso, verificamos a ausência de alguns pontos na discussão como: i) em nenhum momento do Grupo focal foi expressa uma fala que considerasse o contato com a família do aluno com deficiência visual e um trabalho em comum; ii) não foi feita qualquer referência a uma possível conversa entre as diferentes disciplinas, em algum tipo de prática interdisciplinar que promovesse a construção de um conhecimento que facilitasse o processo de ensino-aprendizagem dos alunos com deficiência visual; iii) não houve nenhuma 
menção às questões relativas às políticas públicas como participante do processo de facilitar a inclusão do aluno com deficiência visual no processo de ensino.

A ausência desses temas nos DSCs reflete a falta de contato com a realidade escolar e o fato que esses estágios se dão como atividades isoladas dessa realidade

Dessa forma concluímos que o ensino de Física para alunos com deficiência visual ainda não se mostra relevante do ponto de vista sócio-cultural para o grupo de licenciandos, o que, segundo Sá (1996), é um dos respaldos para afirmar que um fenômeno possa ser gerador de representação social.

O fato de o ensino de Física para alunos com deficiência visual não se apresentar como uma representação social mostra que a idéia de cegos estudarem Física em abordagens mais amplas ainda não é compartilhada pelo coletivo. Se existe uma representação em torno dos alunos com deficiência visual, é que qualquer ação na escola pode até incluí-los ao grupo de alunos, porém eles continuam sendo encarados como diferentes.

Se o ensino de Física para alunos com deficiência visual, não é ainda uma representação social, ou seja, não faz parte do senso comum, cabe aos professores e pesquisadores interessados nesse tema transformá-lo em uma representação social reificada, assegurando um referencial teórico que a sustente, permitindo sua multiplicação pelos profissionais de ensino de ciências.

\section{CONSIDERACOESS FINAIS}

O foco deste trabalho foi promover uma meta-reflexão em torno da eventual contribuição que a disciplina Ensino de Física e Inclusão Social oferece à formação dos Licenciandos de Física. A pesquisa se configurou a partir das falas coletadas de um grupo de licenciandos, a partir da organização de um Grupo Focal. A técnica do Grupo Focal possibilita que a discussão em torno de um tema ocorra de uma forma dialética, ou seja, numa sucessão de teses e antíteses, sem necessariamente demandar uma síntese do assunto, mas permitindo a exposição de idéias que, de uma forma mais espontânea, são direcionadas pela discussão do grupo a cada novo embate. O objetivo do trabalho é identificar, nas falas dos licenciandos, possíveis representações sociais sobre a inclusão de alunos com deficiência visual no ensino básico. Nesse sentido os dados coletados foram analisados com a técnica do Discurso do Sujeito Coletivo, a fim de possibilitar a identificação de uma fala mais alinhada com as possíveis representações sociais identificadas no grupo.

Durante a realização do Grupo Focal, o tema em questão foi explicitamente inserido pelo mediador em diferentes momentos. No entanto verificamos que grande parte da discussão se referiu aos caminhos da docência e a como o professor deve trilhá-los a fim de superar problemas e dificuldades. O tema inclusão de deficientes visuais mobilizou muito a discussão em torno da questão de que, ao incluí-los, o professor faz sacrifícios de vários níveis. Desde a participação em 
cursos específicos até a reorganização de seu planejamento de curso, o professor deve se dedicar à busca de estratégias que permitam a transposição de certos conteúdos considerados difíceis para o deficiente visual. Dentre esses conteúdos, ótica e magnetismo são os considerados mais difíceis de ensinar a uma deficiente visual. Entretanto parece bastante significativo que esses mesmos conteúdos sejam aqueles com os quais os licenciandos se sintam menos à vontade.

Até por conta dessas dificuldades que os deficientes visuais teriam segundo os licenciandos, uma segunda ideia que aparece com muita força e é encarada de forma muito natural, é que esses alunos não podem aprender tudo. Para o grupo, a Física é entendida como uma disciplina que demanda um rigor tal que não pode haver rompimento. Tal limitação se refletirá em suas escolhas profissionais, ou seja, os deficientes visuais não podem exercer todas as profissões.

Concluindo, o ensino de Física a deficientes visuais parece não mobilizar tanto os licenciandos quanto as dificuldades que ele representa. Ou seja, o ensino de Física a um deficiente visual ainda não possui uma relevância sócio-cultural para o grupo escolhido. Segundo Sá (1995), um dos argumentos para afirmar que um fenômeno é gerador de representação social é a mobilização que ele provoca. A mobilização do grupo se deu em torno da idéia de que o ensino de Física demanda rigor e formalidade pedagógica nos moldes tradicionais, para garantir o processo de aprendizagem da disciplina. Qualquer ação que rompa esse padrão, mesmo que para viabilizar a inclusão de deficientes, é vista como um esforço extra para o professor e pode comprometer o ensino de toda a turma. Essa visão rigorosa do ensino de Física é uma representação social forte e os deficientes visuais são vistos como diferentes, para os quais ensino de Física ainda não parece algo natural como o é para alunos sem deficiências.

Esse quadro evidencia que as reformas legais referentes à inclusão social por si só não garantem as mudanças desejadas e para as quais foram criadas, nesse caso a inclusão de deficientes visuais no ensino regular. Para promover e garantir acessibilidade e inclusão, além de normatizações, é necessário que pessoas portadoras de diferenças deixem de ser classificadas segundo Duschatzky \& Skliar (2000), como o pessoas que não são como nós e, portanto, podem ser enquadradas em aparatos pedagógicos, assistenciais ou terapêuticos que os enquadram em nossa cultura - em nosso sistema de necessidades - em nossa "normalidade".

É necessário problematizar a inclusão do deficiente visual cada vez mais, a partir de trabalhos, discussões e da aproximação dos licenciandos de todas as áreas com as distintas formas de diferenças. Em função desses resultados, no que se refere à disciplina Ensino de Física e Inclusão Social, pretendemos intensificar a prática docente na realidade de escolas e adotar a dinâmica do Grupo Focal como uma metodologia para promover a discussão do tema, segundo os referenciais teóricos adotados. 


\section{REFERÊNCIAS}

BRASIL, Ministério da Educação. (1996). Lei de Diretrizes Bases. Diário Oficial da República Federativa do Brasil. Brasília.

CACHAPUZ, A. F. Investigação em Didática das Ciências em Portugal: um balanço crítico. In: Pimenta, S. G. (org). Didática e formação de professores: percursos e perspectivas no Brasil e em Portugal. São Paulo, Cortez, 2008, p. 205-240

CAMARGO B.V, WACHELKE JFR, Aguiar A. O desenvolvimento metodológico das pesquisas sobre representações sociais em jornadas internacionais de 1998 a 2005. In. Moreira ASP, Camargo BV. Contribuiçoes para a teoria e o método de estudos das representaçoes sociais. João Pessoa: Editora Universitária da UFPB, 2007

CAMARGO, E. P.de, Ensino de Física e deficiência visual: Dez anos de investigações no Brasil.São Paulo: Plêiade/FAPESP, 2008

CLASER, E. A. Projeto de educação inclusiva (Pr): propostas para a educação na diversidade. Dissertação (Mestrado em Engenharia de Produção) - Programa de pós-graduação em Engenharia de Produção, Universidade Federal de Santa Catarina, Florianópolis: 2001

DUSCHATZKY, S. e SKLIAR, C. Os nomes dos outros: reflexões sobre os usos escolares da diversidade. Educação e Realidade. Porto Alegre. v.25 n.2 jul/dez.2000.

FREITAS, S. N. e CASTRO, S. F. Representação social e educação especial: a representação dos professores de alunos com necessidades educativas especiais incluidos na classe comum do ensino regular. Retirado em 29/05/2004 em: http://educacaoonline.pro.br

FREIRE, Paulo. Pedagogia do Oprimido. Rio de Janeiro: Ed. Paz e Terra, 1987

JODELET, D. (Org.) As Representações Sociais. Rio de Janeiro: EdUERJ, 2001.

GONDIM, S. M. G. Grupos Focais como Técnica de Investigação, Paidéia, 2003,12(24), 149-161

GONDIM, S. M. G. O Discurso, a Análise do Discurso e a Metodologia do Discurso do Sujeito Coletivo na Gestão Intercultural, Cadernos Gestão Social, 2009, v.2, n.1, pg.9

LEFÈVRE F. \& LEFÈVRE AMC. Os novos instrumentos no contexto da pesquisa qualitativa. In: Lefèvre F., Lefèvre A.M.C., Teixeira J.J.V. (orgs). O discurso do sujeito coletivo: uma nova abordagem metodológica em pesquisa qualitativa. Caxias do Sul: EDUCS; 2000. p. 11-35.

MINAYO, M. C. S., O Desafio do Conhecimento: Pesquisa Qualitativa em Saúde. São Paulo: Editora Hucitec/Rio de Janeiro: ABRASCO. 1992.

MOSCOVICI S. A representação social da psicanálise. Tradução de Álvaro Cabral. Rio de Janeiro (RJ): Zahar; 1978.

MOLINER, P. ISA: Introduction per scénario ambigu - Une méthode pour l'étude des représentations sociales. Révue internacionale de psychologie sociale. 2, 1993, 7-21

SÁ, C. P. Núcleo central das Representações Sociais. Petrópolis: Vozes, 1996

SASSAKI, R. K. Inclusão. Construindo uma sociedade para todos. Rio de Janeiro: WVA,1997.

STAINBACK, S.; STAINBACK, W. Inclusão: um guia para educadores. Porto Alegre: Artmed, 2000.

UNESCO (1994). Declaração de Salamanca sobre Princípios, Politicas e Práticas na Área das Necessidades Educativas Especiais, Salamanca. Em http//www.dominiopublico.gov.br.

Data de Recebimento: 06/12/2010

Data de Aprovação: 05/08/2011

Data da Versão Final: 10/08/2011 
